\title{
The analysis of disperse and elemental composition of dust from drobestry installations of foundry at the production of construction structures for altitude buildings
}

\author{
Irina Ivanova ${ }^{1,{ }^{*}}$ Elena Golovina ${ }^{1}$, Kirill Kulakov $^{2}$ and Andrey Sorokin ${ }^{3}$ \\ ${ }^{1}$ Voronezh State Technical University, Moscow Avenue, 14, Voronezh, 394026, Russia \\ ${ }^{2}$ Moscow State University of Civil Engineering, Yaroslavskoe sh. 26, Moscow, 129337, Russia \\ ${ }^{3}$ Moscow Aviation Institute (National Research University), Volokolamskoe highway, 4, Moscow, \\ 125993, Russia
}

\begin{abstract}
In the production of building structures for high-rise buildings, the dangerous and harmful factors of foundry production include high concentrations of dust and harmful gases released at various stages of the process. Disperse and elemental compositions of dust determine the hygienic state of the working area of the foundry. According to experts, the presence of dust of less than 10 microns in size in the air increases the danger of getting occupational diseases, such as pneumoconiosis (silicosis), bronchitis, dermatitis, conjunctivitis. The determination of the granulometric composition of the powder sample provided was carried out by the laser diffraction method realized on a laser particle analyzer Fritsch NanoTec «ANALISETTE 22».
\end{abstract}

\section{Introduction}

In the air environment of foundries in the production of building structures for highrise buildings, in addition to dust, there are large numbers of carbon oxides, carbon dioxide and sulphurous gases, nitrogen and its oxides, hydrogen, aerosols saturated with iron and manganese oxides, hydrocarbon vapors and other [1]. Melting aggregates, heat treatment furnaces, dried for molds, rods and buckets, etc. are sources of contaminants. The foundry shop of machine-building production is located in the urban development. The degree of environmental safety is determined by the microclimate in the zone of shot blasting and the intercore zone of the plant (with dispersion of emissions).

When melting cast iron, in addition to dust, a significant amount of carbon oxides is produced, as well as sulfurous anhydride, hydrocarbons, and nitrogen oxide In induction furnaces in addition to the above ingredients, chlorine and hydrogen fluoride are released, when smelting aluminum. Foundry production is characterized by gas evolution under the influence of the heat of liquid metal on the molding mixtures. Depending on the type of

\footnotetext{
* Corresponding author: ivanova-eco@mail.ru
} 
components of the molding mixtures, benzene, phenol, formaldehyde, furan, cyanide, ammonia, and other toxic substances can be released from them [2].

Dust, the main constituent of which in foundries is silica, is formed during the preparation and regeneration of molding and core mixtures, smelting casting alloys in various melting units, the release of liquid metal from the furnace, out-of-furnace processing and pouring into molds, in the knockout section of the castings, in the process stump and cleaning of casting, in the preparation and transportation of raw bulk materials.

The air condition of the working area of the foundry, as a rule, does not meet the normative hygienic requirements. This is determined by the complexity of the technological processes of production as a whole [3].

The dispersed and elemental composition of the dust also determines the hygienic state of the working zone of the foundry. According to experts, the presence of dust in the air of less than 10 microns in size increases the danger of obtaining occupational diseases: pneumoconiosis (sialicosis), bronchitis due to the low settling rate of dust and its prolonged stay in the air of the working area. In addition, fine dust and dust of less than $10 \mu \mathrm{m}$ creates additional difficulties in dust collection [4].

\section{Materials and Methods}

Large particles of dust linger on the mucosa of the upper respiratory tract, particles with sizes less than 10 microns can penetrate into the alveoli of the lungs, where the main part of them is retained (Table 1). Hazard class $-3, \mathrm{MPC}=0.5 \mathrm{mg} / \mathrm{m}^{3}$.

Suspended particles can cause a toxic effect by one or more of the following three pathways [5]:

1. A particle may be toxic due to its chemical or physical characteristics.

2. A particle may interfere with one or more mechanisms by which the respiratory tract is normally cleaned.

3. A particle may be a carrier of a toxic substance absorbed thereon.

Table 1. Observed impact of suspended particles on the environment and human

\begin{tabular}{|c|c|c|}
\hline $\begin{array}{c}\text { Concentration, } \\
\mathbf{m g} / \mathrm{m}^{3}\end{array}$ & Time interval & Impact result \\
\hline $60-180$ & $\begin{array}{l}\text { Average annual geometric mean, in the } \\
\text { presence of SO2 and moisture }\end{array}$ & $\begin{array}{l}\text { Increased corrosion of steel and zinc } \\
\text { plates }\end{array}$ \\
\hline 150 & A relative humidity of less than $70 \%$ & Reducing visibility to $8 \mathrm{~km}$ \\
\hline $80-100$ & $\begin{array}{c}\text { Simultaneous level of sulphate } \\
\text { precipitation in } 30 \mathrm{mg} /\left(\mathrm{cm}^{2} \text { per month }\right) .\end{array}$ & Increase in mortality by $50 \%$ can occur \\
\hline $100-130$ & Concentration of S02 $120 \mu \mathrm{g} / \mathrm{m}^{3}$ & $\begin{array}{l}\text { Possible increase in the number of } \\
\text { respiratory diseases in children }\end{array}$ \\
\hline 200 & Average daily at SO2> $250 \mu \mathrm{g} / \mathrm{m}^{3}$ & $\begin{array}{c}\text { Diseases of industrial workers can lead } \\
\text { to an increase in absenteeism }\end{array}$ \\
\hline 300 & $\begin{array}{c}\text { Maximum for } 24 \text { hours with } \\
\text { simultaneous concentrations } \mathrm{O} 2>630 \\
\mu \mathrm{g} / \mathrm{m}^{3}\end{array}$ & $\begin{array}{l}\text { Patients with chronic bronchitis will } \\
\text { experience a sharp exacerbation } \\
\text { symptoms }\end{array}$ \\
\hline 750 & Average daily SQ2 $>715 \mu \mathrm{g} / \mathrm{m}^{3}$ & $\begin{array}{c}\text { Can come significant increase in } \\
\text { diseases and deaths }\end{array}$ \\
\hline
\end{tabular}

Provision of safe levels of maximum permissible concentrations of pollutants in the operator's work area shot blasting area and in the wind zone of the foundry is the purpose of this work. 
Due to the fact that the existing dust collection system using cyclones is not effective and there is a multiple exceeding of the maximum permissible concentration (MPC) of dust. The actual efficiency of the dust collectors in the shop is inadequate. In order to further purge the ejection into the intercorpus zone and bring the contaminants in the working area to acceptable levels, the dust collection system can be supplemented with a second "wet" stage.
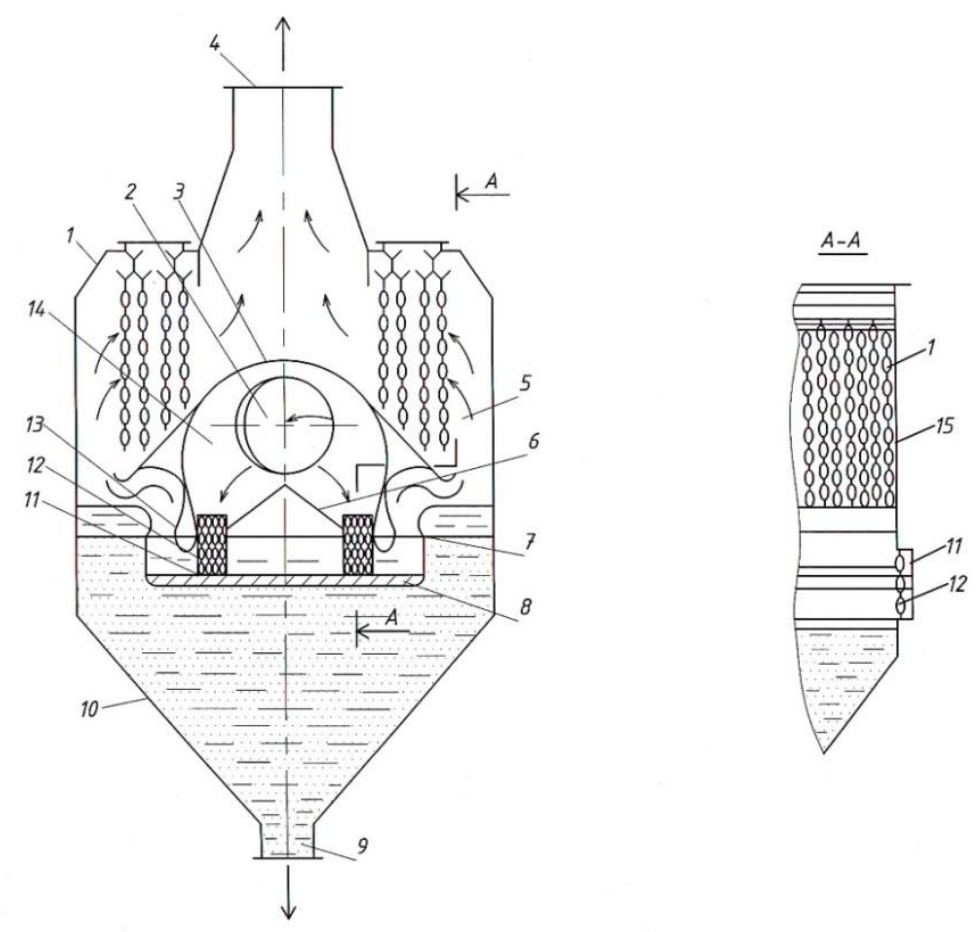

Fig. 1. Wet Dust Collector:

1 - shell; 2 - inlet branch pipe; 3 - baffle; 4 - outlet branch pipe; 5 - clean gas chamber; 6 reflecting plates; 7 - bottom baffle; 8 - louvered grille; 9 - branch pipe for sludge removal; 10 bunker for collection of caught dust; 11 - poket; 12 - blinded loose hanging chains; 13 - upper baffle; 14 - dusty gas chamber; 15 - drift catcher

Authors V.I. Semkin, A.V. Dumnov, N.I. Adzhiev, suggest a device for cleaning emissions, which is developed in the research and design institute for the protection of labor of building materials.

For the dust analysis, the dispersion (granulometric) analysis method was used.

Determination of the granulometric composition of the powder sample provided was carried out by the laser diffraction method implemented on the laser particle analyzer Fritsch NanoTec "ANALISETTE 22" (Fig.2, 3).

To study particles in the analyzer, the principle of comparing laser radiation from samples and the object of research is used. We used Fraungofer model. This model is used only for samples with particles larger than $0.1 \mu \mathrm{m}(100 \mathrm{~nm})$; 


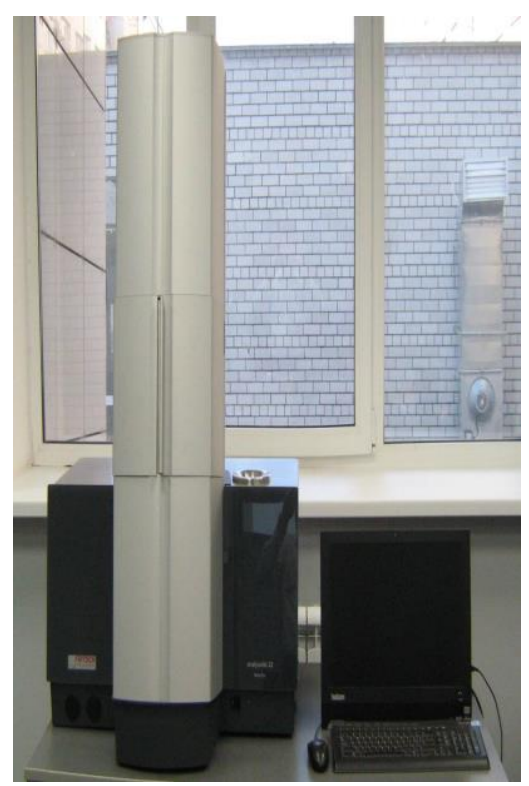

Fig. 2. General view of the laser analyzer Analysette-22 NanoTec (Fritsch, Germany)

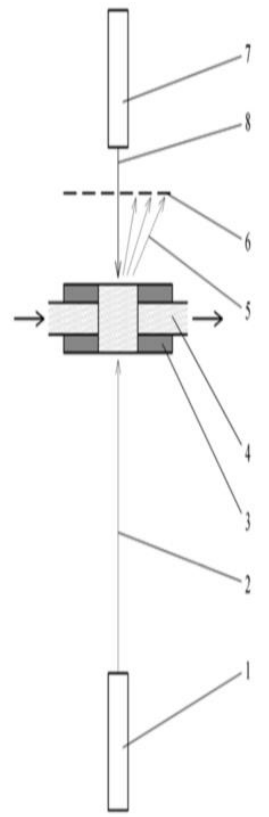

Fig. 3. Optical part of laser particle analyzer Analysette-22 NanoTec:

1 - front laser; 2 - front laser beam; 3 - measuring cell; 4 - dispersed medium containing a sample; 5 - laser-scattered sample; 6 - detector; 7 - back laser; 8 - back laser beam

\section{Results}

Based on the results of the analysis, the granulometric composition of the samples was determined. The results are summarized in Table 2 and are shown in Figure. 4. 
Table 2. The granulometric composition of the sample, the $\%$ content of particles of a certain size.

\begin{tabular}{|l|l|l|l|l|l|}
\hline Value, $\%$ & $\begin{array}{c}\text { particle size, } \\
\boldsymbol{\mu m}\end{array}$ & Value, $\%$ & $\begin{array}{c}\text { particle size, } \\
\boldsymbol{\mu m}\end{array}$ & Value, $\%$ & $\begin{array}{c}\text { particle size, } \\
\boldsymbol{\mu m}\end{array}$ \\
\hline $5.0 \%$ & $<=19.285 \mathrm{mkm}$ & $10.0 \%$ & $<=26.295 \mathrm{mkm}$ & $15.0 \%$ & $<=30.679 \mathrm{mkm}$ \\
\hline $20.0 \%$ & $<=34.802 \mathrm{mkm}$ & $25.0 \%$ & $<=38.617 \mathrm{mkm}$ & $30.0 \%$ & $<=42.615 \mathrm{mkm}$ \\
\hline $35.0 \%$ & $<=46.354 \mathrm{mkm}$ & $40.0 \%$ & $<=50.105 \mathrm{mkm}$ & $45.0 \%$ & $<=53.895 \mathrm{mkm}$ \\
\hline $50.0 \%$ & $<=57.549 \mathrm{mkm}$ & $55.0 \%$ & $<=61.440 \mathrm{mkm}$ & $60.0 \%$ & $<=65.570 \mathrm{mkm}$ \\
\hline $65.0 \%$ & $<=70.497 \mathrm{mkm}$ & $70.0 \%$ & $<=75.998 \mathrm{mkm}$ & $75.0 \%$ & $<=82.355 \mathrm{mkm}$ \\
\hline $80.0 \%$ & $<=89.220 \mathrm{mkm}$ & $85.0 \%$ & $<=97.614 \mathrm{mkm}$ & $90.0 \%$ & $<=115.049 \mathrm{mkm}$ \\
\hline $95.0 \%$ & $<=162.398 \mathrm{mkm}$ & $99.0 \%$ & $<=189.947 \mathrm{mkm}$ & & \\
\hline
\end{tabular}

In table 1 the particle size is fixed. As a result, sample contains $90 \%$ of particles with size less or equal to $115.049 \mu \mathrm{m}$ and $10 \%$ of particles with large size. Particles of this size are dangerous for human health, as they cause pneumoconiosis.

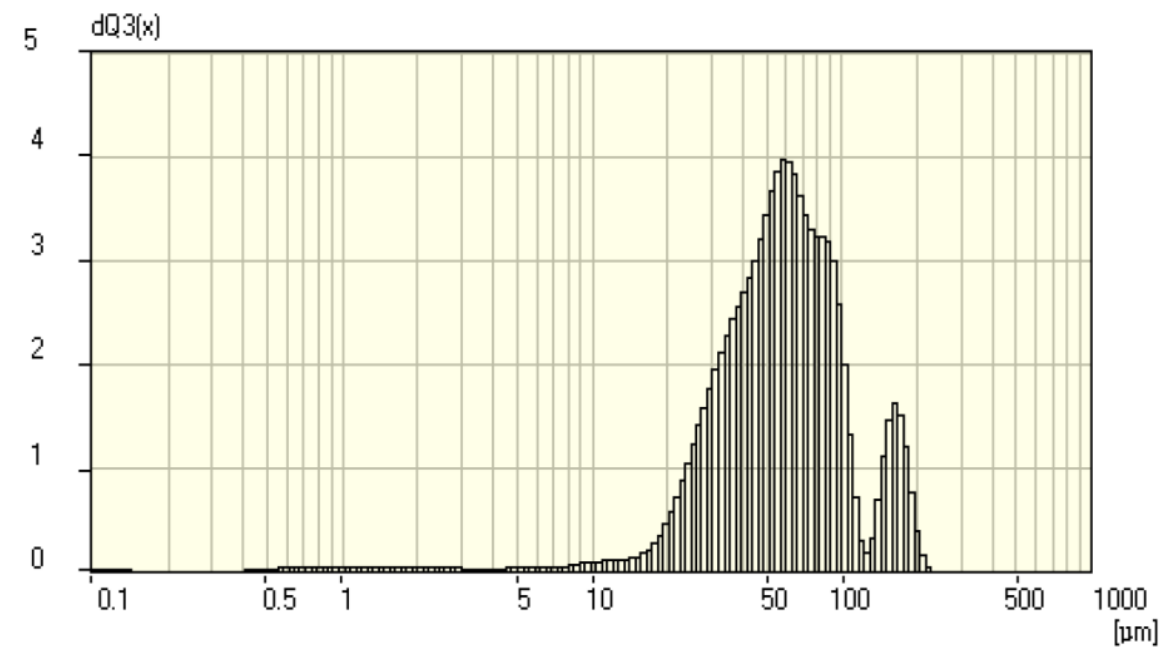

Fig. 4. Graphical results of dispersion analysis of distribution of dust particles.

The sedimentation method does not answer the question of how much particles of a certain size there are in a given system; it only shows the percentage of particles that have dimensions that are in the interval between one radius and another.

In order to estimate the dust parameters more accurately: dispersion and element composition, the X-ray phase analysis method was used, in which the following equipment was used:

1. X-ray diffractometer "DRON 04".

2. X-ray diffractometer "Radian DR-02".

3. Wave X-ray fluorescence spectrometer "Bruker S8 Tiger".

The study of the structure of dust,

The study of the structure of the dust formed during X-ray spectral analysis showed, that it, as a rule, has a form, which makes it possible to conditionally consider it spherical. When the dust particles fall, they always try to occupy the position corresponding to the greatest resistance in the air, this form contributes to their settling in the atmosphere and in inertial dust collectors. However, the presence of particles smaller than $10 \mu \mathrm{m}$ indicates their considerable settling time and the need for highly effective post-treatment systems. As a result, $86.2 \%$ of the sample is less than $100 \mu \mathrm{m}, 13.8 \%$ is heavy particles larger than $100 \mu \mathrm{m}$. Particles of this size are dangerous for human health, as they cause pneumoconiosis, and in the presence of a $\mathrm{SiO} 2$ film of silicosis [6]. 
A scanning electron microscope is supplemented by spectrometers of both varieties. The quantitative analysis is based on a comparison of the intensity of the characteristic X-ray radiation from the sample under study and standards of samples of known composition. The results of calculation of concentrations and absolute random errors were displayed on the display and the printer.

In the course of the experiment, the operational error control of the measurement results for each of the chemical elements was carried out.

Control is carried out by estimating the concentrations of elements in existing standards. Initially, an analysis was performed to determine the phase composition of the substance using a DRON 04 diffractometer with $\mathrm{CoK} \alpha$ radiation $(1.789 \AA)$ in the range of angles $2 \Theta(10-110)^{\circ}$ at $\mathrm{U}=29 \mathrm{kV}, \mathrm{I}=26 \mathrm{~mA}$. Table 2 and Figure 3 show an X-ray spectral analysis of the dust collected from the shot blasting section of the casting.

Table 2. X-ray spectral analysis data on the «Bruker S8 Tiger» equipment.

\begin{tabular}{|c|c|c|c|c|c|c|c|c|c|c|c|c|c|c|c|c|c|c|}
\hline San & $\frac{a}{3}$ & $\frac{8}{2}$ & $\overbrace{0}^{0}$ & $e_{0}^{0}$ & $\frac{\delta}{0}$ & $\underbrace{0}_{1}$ & $\underbrace{0}_{0}$ & $\stackrel{0}{0}$ & t) & $\frac{0}{e^{0}}$ & 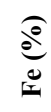 & $\frac{\widehat{\varrho}}{e_{z}}$ & $\underset{\Xi}{\varrho}$ & $\begin{array}{l}0 \\
\mathrm{e}\end{array}$ & (5) & $\frac{\partial}{\grave{N}}$ & $\frac{a}{e^{0}}$ & \\
\hline $\begin{array}{l}\text { Dust fi } \\
\text { blastin }\end{array}$ & $\frac{F}{0}$ & 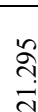 & $\underset{\stackrel{\Delta}{\Delta}}{\stackrel{\Delta}{\Delta}}$ & ¿ & ஜ̊ & $\stackrel{\infty}{0}$ & $\stackrel{?}{\stackrel{f}{0}}$ & $\stackrel{2}{\circ}$ & $\bar{n}$ & ลี & $\begin{array}{l}\tilde{n} \\
\tilde{n} \\
\infty \\
+\end{array}$ & $\stackrel{\text { ले }}{0}$ & $\stackrel{2}{0}$ & $\begin{array}{l} \pm \\
\vdots \\
0\end{array}$ & ลี & 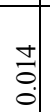 & 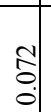 & $\infty$ \\
\hline
\end{tabular}

The manifestation of a large number of reflexes indicates the presence of several phases in the sample. To determine the phases, a diffraction measurement database "PDF2012" was usedDue to the large number of possible elements and phases, X-ray spectral analysis was used to reduce the possible phase variants of the sample. The survey was performed twice on the Radian DR-02 diffractometer with the function of X-ray fluorescence analysis.

X-ray spectral analysis indicated the presence of a phase of iron (Fe), titanium (Ti) and chromium $(\mathrm{Cr})$. The iron $(\mathrm{Fe})$ phase predominates $(78 \%)$. Due to the lack of the possibility of determining the "light" elements on the "Radian DR-02" diffractometer, the X-ray spectral analysis was carried out on the "Bruker S8 Tiger" wave X-ray fluorescence spectrometer at the CCU of the NO VSU.

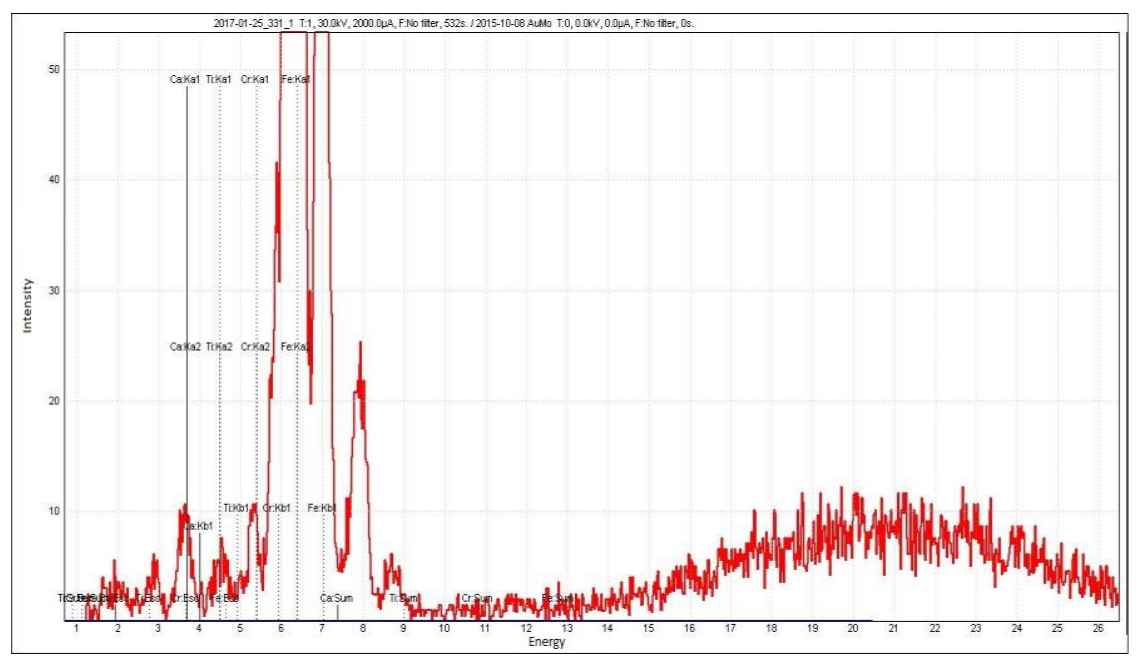

Fig. 5. X-ray spectral analysis of the sample on the diffractometer "Radian DR-02". 


\section{Discussions}

X-ray spectral analysis showed a more accurate percentage of elements in the sample. The presence of $\mathrm{Al}, \mathrm{Si}, \mathrm{Cr}, \mathrm{Fe}$ reduces the search time in the "PDF-2012" database for phase analysis. The phases of oxides can only be detected using the X-ray phase analysis method. The remaining elements have a small percentage value.

The results of the analysis show that in the foundries there is a presence of dispersed dust of less than $10 \mu \mathrm{m}$, while $78 \%$ of iron (Fe) is present in the shot blasting section in the dust. Also, the analysis of dust concentration in operator's work area revealed significant excess of the MAC of the working zone. The dispersion of the dust composition was evaluated, which showed a large amount of fine dust (less than 10 microns) of $86.2 \%$.

In addition to dust in emissions of the foundry there are harmful gases: sulfur oxides (SO2, SO3), oxides of nitrogen $(\mathrm{NO} 2, \mathrm{NO})$, carbon oxides of $\mathrm{CO}$ and $\mathrm{CO} 2$, phenol $(\mathrm{C} 6 \mathrm{H} 5 \mathrm{OH})$, formaldehyde (HCHO), benz (a) pyrene (C20H12) [10,11]. Since the results of the parameter estimation are unstable, we had to use more accurate methods with the help of a diffractometer.

\section{Conclusion}

Dust structure research showed: when crushing, $86.2 \%$ of the dust produced has a fraction size of less than $100 \mu \mathrm{m}$, i.e. refers to medium and fine dust, having a settling rate of less than $7 \mathrm{~cm} / \mathrm{s}$.

It is established that the iron (Fe) content in the elemental composition of all dust is $78 \%$, which happens due to the processing of castings with iron shot. The phase composition was refined in the second stage of the research with the help of the Radian DR-02 diffractometer and the diffraction measurement database "PDF-2012".

\section{References}

1. A.N. Boldin, Foundry, 3, 33-34 (2005)

2. O. Kalinina, O. Valebnikova, Advances in Intelligent Systems and Computing, 692, 1315-1322 (2018) DOi - 10.1007/978-3-319-70987-1_139

3. I.A. Ivanova, Bulletin of the DGTU, 2 (45), 200-204 (2010)

4. E.I. Golovina, I.A. Ivanova, S.A. Ivkov, Internet Journal of Science, 2 (39), 62 (2017)

5. V.L. Murzinov, V.Ya. Manokhin, E.I. Golovina, Polimatic network electronic scientific journal of the Kuban State Agrarian University, 130, 155-172 (2017)

6. E.I. Golovina, I.A. Ivanova, M.V. Manokhin, Vestnik of the Don State Technical University, 2 (89), 141-148 (2017) 